\title{
Comparison Between a Self-Administered and Supervised Version of a Web-Based Cognitive Test Battery: Results From the NutriNet-Santé Cohort Study
}

Karen E Assmann ${ }^{1}$, MPH, MSc; Marion Bailet ${ }^{1}$, MSc; Amandine C Lecoffre ${ }^{1}$, MSc; Pilar Galan ${ }^{1}$, MD, PhD; Serge Hercberg ${ }^{1,2}$, MD, PhD; Hélène Amieva ${ }^{3}$, PhD; Emmanuelle Kesse-Guyot ${ }^{1}$, PhD

\footnotetext{
${ }^{1}$ Université Paris 13, Equipe de Recherche en Epidémiologie Nutritionnelle (EREN), Centre d'Epidémiologie et Statistiques Sorbonne Paris Cité, Inserm (U1153), Inra (U1125), Cnam, COMUE Sorbonne Paris Cité, Bobigny, France

${ }^{2}$ Département de Santé Publique, Hôpital Avicenne, Bobigny, France

${ }^{3}$ Inserm U897, Université Bordeaux, Bordeaux, France
}

\section{Corresponding Author:}

Karen E Assmann, MPH, MSc

Université Paris 13, Equipe de Recherche en Epidémiologie Nutritionnelle (EREN)

Centre d'Epidémiologie et Statistiques Sorbonne Paris Cité

Inserm (U1153), Inra (U1125), Cnam, COMUE Sorbonne Paris Cité

UFR SMBH

74 rue Marcel Cachin

Bobigny, 93017

France

Phone: 33148387378

Fax: 33148388931

Email: k.assmann@eren.smbh.univ-paris13.fr

\section{Abstract}

Background: Dementia is a major public health problem, and repeated cognitive data from large epidemiological studies could help to develop efficient measures of early prevention. Data collection by self-administered online tools could drastically reduce the logistical and financial burden of such large-scale investigations. In this context, it is important to obtain data concerning the comparability of such new online tools with traditional, supervised modes of cognitive assessment.

Objective: Our objective was to compare self-administration of the Web-based NutriNet-Santé cognitive test battery (NutriCog) with administration by a neuropsychologist.

Methods: The test battery included four tests, measuring, among others aspects, psychomotor speed, attention, executive function, episodic memory, working memory, and associative memory. Both versions of the cognitive battery were completed by 189 volunteers (either self-administered version first, $n=99$, or supervised version first, $n=90$ ). Subjects also completed a satisfaction questionnaire. Concordance was assessed by Spearman correlation.

Results: Agreement between both versions varied according to the investigated cognitive task and outcome variable. Spearman correlations ranged between .42 and .73. Moreover, a majority of participants responded that they "absolutely" or "rather" agreed that the duration of the self-administered battery was acceptable $(184 / 185,99.5 \%)$, that the tasks were amusing $(162 / 185,87.6 \%)$, that the instructions were sufficiently detailed $(168 / 185 ; 90.8 \%)$ and understandable $(164 / 185,88.7 \%)$, and that they had overall enjoyed the test battery $(182 / 185,98.4 \%)$.

Conclusions: The self-administered version of the Web-based NutriCog cognitive test battery provided similar information as the supervised version. Thus, integrating repeated cognitive evaluations into large cohorts via the implementation of self-administered online versions of traditional test batteries appears to be feasible.

(J Med Internet Res 2016;18(4):e68) doi: 10.2196/jmir.4862

\section{KEYWORDS}

cognition; executive function; internet; cohort studies 


\section{Introduction}

More than one third of the population in more developed world regions will be aged 60 years and older by the year 2050, according to estimates published in a United Nations report [1]. This population aging is taking place worldwide and is associated with a significant increase in the burden of age-related cognitive decline [2]. According to the 2009 World Alzheimer Report [3], the number of dementia cases is estimated to double every 20 years. Given the major social and economic consequences of dementia, age-related cognitive decline is one of the key public health problems of our time.

Current evidence consistently indicates that Alzheimer's disease diagnoses are preceded by a very long pre-dementia phase [4-8]. Moreover, various studies suggest that this phase begins relatively early in life, indicating that studies on determinants of cognitive aging should focus on midlife factors [9-15]. Hence, longitudinal studies with available data on midlife risk factors and with repeated cognitive data are well adapted for the investigation of potential targets for early preventive measures [11]. Yet, the high logistical and personnel-related costs of traditional neuropsychological evaluations (ie, neuropsychological interviews or paper-and-pencil tests with supervision by trained personnel [16]) present major feasibility problems for epidemiological studies with large sample sizes. Thus, there has been a growing interest in the development of computerized cognitive evaluations as these allow for standardized, repeated procedures, systematic scoring, and automated saving or data management $[17,18]$.

Two recent reviews of the literature have counted a total of 13 different computerized cognitive test batteries that are adapted to the context of age-related cognitive impairment or dementia $[17,18]$. Of these, only four are fully self-administered: the Computer-Administered Neuropsychological Screen for Mild Cognitive Impairment (CANS-MCI) battery, the Central Nervous System Vital Signs (CNS Vital Signs) battery, the MicroCog: Assessment of Cognitive Functioning (MicroCog) battery, and the Computer Assessment of Mild Cognitive Impairment (CAMCI) battery. One further battery, the Cambridge Neuropsychological Test Automated Battery (CANTAB) was described as "largely independent of verbal instructions." Such fully self-administered batteries that do not rely on examiners to explain instructions or to supervise the completion of tasks are of interest for multiple reasons. Logistical and personnel costs can be further reduced, effort and time investment for participants are lower (since testing can be done at home), and an integration of cognitive evaluations into large-scale epidemiological studies is possible. However, it is important to assess the concordance of such a fully self-administered mode of administration with a "supervised" mode of administration. A supervised mode of administration is characterized by the presence of a trained examiner who gives test instructions, supervises the completion of the battery, and is available to help in the case of comprehension problems.

The objective of this study was to compare these two types of administration (fully self-administered versus supervised) with respect to a cognitive test battery (ie, NutriCog) that was specifically developed for the French NutriNet-Santé cohort.

\section{Methods}

\section{Choice of the Cognitive Tasks to Include in the NutriCog Battery}

The selection of the cognitive tasks included in our battery was based on a literature review of available computerized neuropsychological batteries [17,18]. Three important considerations guided our choices. First, the tasks had to be feasible in the context of an entirely Web-based battery (in relation to connection speed limitations, the use of mouse and keyboard instead of stylus pens, etc). Second, given our objective to study long-term age-related cognitive decline starting from midlife, the tasks had to reflect cognitive processes that have been shown to show slight functional changes in early aging (ie, episodic memory, attention/working memory, and highly integrated executive functions) [16,19]. Third, the selected tasks had to be derived from robust, previously validated neuropsychological paradigms. The tasks that were finally chosen to be part of our battery are described in Table 1. Briefly, the first task ("Click") consists of connecting numbers (in ascending order) as fast as possible, the second task ("Maze") consists of discovering a labyrinth route while respecting a certain number of rules, the third task ("Cards") is a matching-to-sample task presented as a card game, and the fourth task ("Marbles") consists of memorizing and recalling the color pattern of several marbles with a specific location on the screen. The specific realizations of all tasks except the Click-task are randomly generated at the beginning of each session and were thus not identical across the two modes of administration (fully self-administered/supervised). For example, participants were confronted with distinct labyrinth routes for each of the two completions of the test battery (fully self-administered/supervised). 
Table 1. Description of the cognitive test battery, NutriNet-Santé Study.

\begin{tabular}{|c|c|c|c|}
\hline $\begin{array}{l}\text { Task } \\
\text { name }\end{array}$ & Cognitive processes involved & Task description & Outcome variables \\
\hline Click & $\begin{array}{l}\text { Visual-motor coordination, } \\
\text { psychomotor speed, selective } \\
\text { attention }\end{array}$ & $\begin{array}{l}\text { Numbers (1-5) are connected in ascending order (as fast as } \\
\text { possible). A set of three consecutive trials is completed. The } \\
\text { task is similar to part A of the Trail Making Test }{ }^{\mathrm{a}} \text {. }\end{array}$ & Mean time taken (seconds) \\
\hline $\begin{array}{l}\text { Maze } \\
(\text { Maze A, } \\
\text { Maze B) }\end{array}$ & $\begin{array}{l}\text { Episodic memory, procedural } \\
\text { memory, working memory, vi- } \\
\text { suospatial attention, executive } \\
\text { function (planning, inhibition, } \\
\text { mental flexibility) }\end{array}$ & $\begin{array}{l}\text { A labyrinth path is discovered by the participant, who has to } \\
\text { respect several different rules. First, a set of three consecutive } \\
\text { trials is completed. Next, after performing the Cards task, the } \\
\text { Marbles task, and a supplemental unrelated task (with a dura- } \\
\text { tion of a few minutes), the participant is presented with a final } \\
\text { (fourth) trial. The task was adapted from the Groton Maze } \\
\text { Learning test }{ }^{\text {b. }} \text {. }\end{array}$ & $\begin{array}{l}\text { Total time taken (seconds); number of } \\
\text { total clicks (n); number of total errors } \\
\text { (n)-These variables are calculated sep- } \\
\text { arately for the initial } 3 \text { trials (Maze A) } \\
\text { and the final trial (Maze B) }\end{array}$ \\
\hline Cards & $\begin{array}{l}\text { Working memory, executive } \\
\text { function (inhibition, mental } \\
\text { flexibility), sustained attention }\end{array}$ & $\begin{array}{l}\text { Matching-to-sample (one-back type) task: cards are continu- } \\
\text { ously presented to the participant, who must decide whether } \\
\text { or not a presented card is the same as the one shown just be- } \\
\text { fore. }\end{array}$ & $\begin{array}{l}([1 / \text { (incorrect answers }+1000)] / \text { time }) * \\
100,000\end{array}$ \\
\hline Marbles & $\begin{array}{l}\text { Visual memory, episodic } \\
\text { memory, associative memory }\end{array}$ & $\begin{array}{l}\text { The participant is presented with a central marble and several } \\
\text { colored peripheral marbles. First, the color patterns of each } \\
\text { marble have to be memorized. Second, the colors of the pe- } \\
\text { ripheral marbles disappear and the central marble continuously } \\
\text { takes on different colors, and the participant has to click on } \\
\text { the peripheral marble corresponding to the color shown. }\end{array}$ & $\begin{array}{l}([1 / \text { (incorrect answers }+1000)] / \text { time }) * \\
100,000\end{array}$ \\
\hline
\end{tabular}

${ }^{a}$ Details on the Trail Making Test have been published elsewhere [16].

${ }^{b}$ Details on the Groton Maze Learning Test have been published elsewhere [20].

\section{Development of an Operational Version of the NutriCog Battery}

In order to obtain our final Web-based instrument, the NutriCog battery, the following working steps were undertaken: (1) adaptation of the task instructions to a self-administered computerized framework, (2) prototype development, (3) pilot testing, and (4) revision of the prototype. Pilot testing consisted of assessing comprehensibility of the instructions, timing, and potential technical glitches. These pilot tests have been conducted in our research institute, within a sample of individuals with varying age, education level, and sex.

Lessons that we have learned during the development of the operational version of our battery include the importance of constructive exchanges within an interdisciplinary team of neuropsychologists, epidemiologists, and computer scientists in order to find solutions that are relevant in terms of neuropsychological paradigms, the planned epidemiological investigations, and feasibility in terms of software development. Moreover, multiple rounds of pilot testing within samples of individuals with diversified characteristics were necessary to identify software errors and comprehensibility problems, and to calibrate the display times, for example, messages during the Maze task or cards during the Cards task.

\section{Design of the Comparison Study}

In order to compare the self-administered mode of the NutriCog Web-based cognitive battery to a supervised mode of this same battery, we conducted a comparison study in a subsample of the NutriNet-Santé cohort. Each participant of this subsample was asked to perform the test battery twice (ie, in both the self-administered mode and the supervised mode), with an intermission of about 2 months (mean 73.2, SD 17.2 days) in between the two realizations. In order to account for learning effects that have to be expected when repeatedly administering cognitive tests [16], we randomized participants into two study groups, differing in the order of administration of the test battery version. The respective study groups were named SA-SU (self-administered version first, supervised version second) and SU-SA (supervised version first, self-administered version second). The NutriCog test battery was available on the NutriNet-Santé personal Internet page of each participant. The volunteers were asked to use at least 12-inch monitors for optimal visualization of the tests, to use a mouse, and to be in a quiet place without any disruption.

Prior to administering the battery of cognitive tests, the participants were asked to complete a short questionnaire assessing their current mood. At the end of each round of assessment (ie, self-administered version and supervised version), participants were presented with a process evaluation questionnaire in order to provide feedback on the test battery. The expected time to complete the battery in full was 20-25 minutes (15-20 minutes for the cognitive tests and 5 minutes for the questionnaires). Finally, after the participants had completed both versions of the test battery, they were presented with a satisfaction questionnaire, designed to collect information on the acceptability of the duration of each version of the battery, the difficulty of the tasks, the presentation and comprehensibility of the instructions, and the overall appreciation of the test battery.

\section{Administration of the Two Versions of the Test Battery}

The self-administered version was completed by the volunteers while alone, following the instructions given on the webpage. The supervised version was completed with assistance by a trained neuropsychologist, who made a home-visit appointment 
with each volunteer. The instructions were given orally by the neuropsychologist, who was also available to answer any upcoming questions concerning the instructions. All administrations of the supervised version of the battery were realized by the same neuropsychologist. There were no other differences between the two assessment rounds.

\section{Selection of Participants for the Comparison Study}

The selection process for our study sample is presented in Figure 1. We selected a subsample of 1416 participants of the NutriNet-Santé cohort, via a stratified randomization procedure, using sex, age group ( $<50$ years, $\geq 50$ years), and educational level ( $\leq 2$ years of higher education, $>2$ years of higher education) as stratification variables. Among those subjects who agreed to participate, we selected 208 individuals with varying sex, age, and educational level (our pre-defined objective was to obtain a final sample of approximately 200 participants) and randomly attributed them to the two study groups. Of these 208 subjects, 14 were excluded because they did not validate both versions of the test battery, and 5 individuals were excluded because serious technical (ie, computer-related) problems had occurred as they completed the battery. Thus, our final study sample consisted of 189 participants (group SA-SU: n=99; group SU-SA: n=90).

Figure 1. Selection of participants and attribution to the study groups SA-SU (self-administered version first, supervised version second) and SU-SA (self-administered version first, supervised version second).

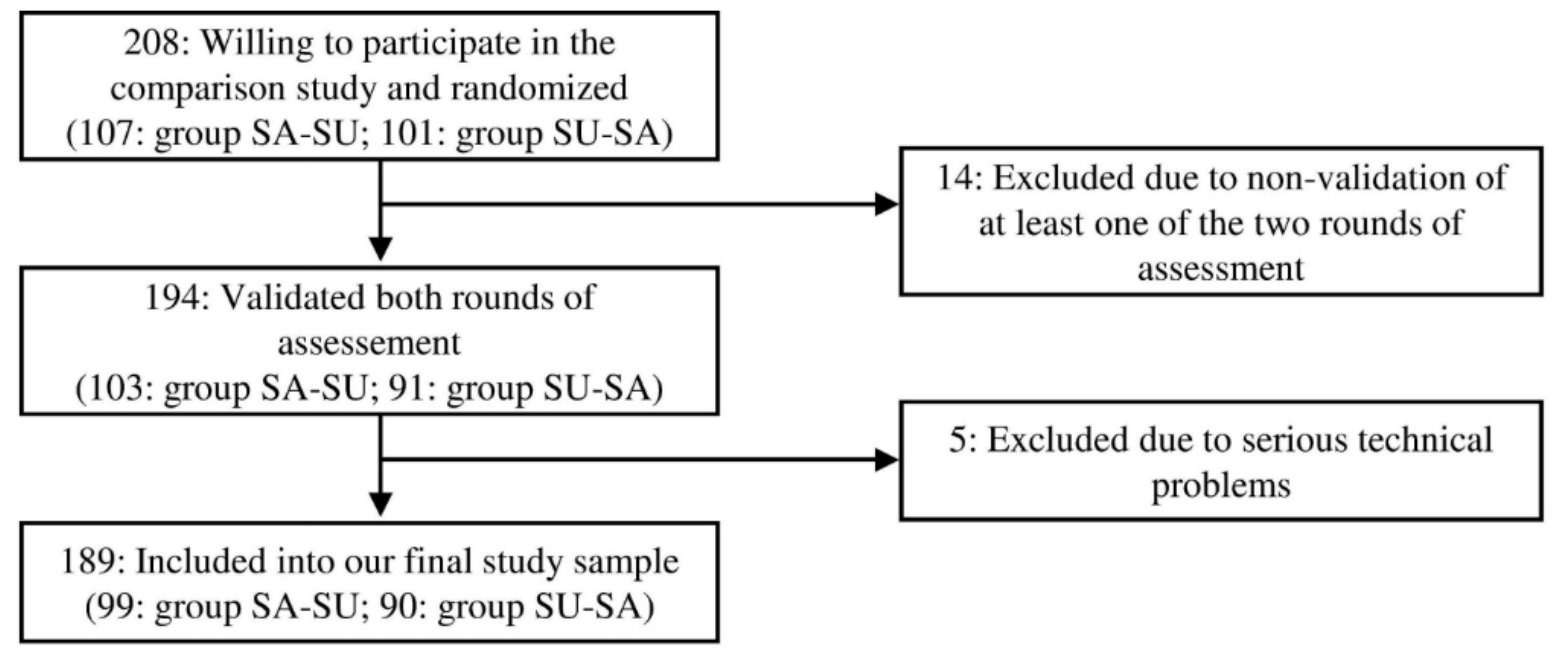

\section{Statistical Analyses}

\section{Creation of Composite Variables}

For the Cards and Marbles tasks, composite variables relating the number of incorrect answers to the time taken were created, as both the quality of the responses and the rapidity of task completion are important for the evaluation of performances on these tasks. The following formula was applied in order to relate incorrect answers to time while obtaining readable (ie, not too small) values and improving the normality of the distribution: ([1/(incorrect answers+1000)] /time) $* 100,000$. For these composite variables, higher scores indicate higher performances, while for all other variables, lower scores indicate higher performances.

\section{Descriptive Analysis}

Participant characteristics were presented as $\mathrm{n}$ and $\%$ or $\mathrm{p} 50$ and p25, p75 (ie, $50^{\text {th }}$ and $25^{\text {th }}, 75^{\text {th }}$ percentile) and differences across study groups were tested via chi-square tests and (nonparametric) Wilcoxon rank-sum tests, respectively. In order to detect potential learning effects, median performances on the first administration and on the second administration of the battery were tabulated and compared via nonparametric paired tests (Wilcoxon signed-rank tests). Furthermore, we tabulated median performances according to test battery version (self-administered, supervised) as p50 and p25, p75. Finally,
Spearman correlations between the different cognitive outcomes variables were tabulated.

\section{Concordance Analysis}

Concordance between the two versions of the test battery was estimated via Spearman correlation coefficients (presented with their $P$ values). We decided to use Spearman correlations as our main statistical indicators in order to facilitate a comparison of our results with other methodological articles on computerized cognitive test batteries, which mostly report Pearson or Spearman correlations [18]. Spearman correlations were more adapted to our data than Pearson correlations as the cognitive outcome variables were not normally distributed.

Spearman correlations were presented for the whole study sample and stratified by age ( $<50$ years, $\geq 50$ years), educational level ( $\leq 2$ years of post-high school education, $>2$ years of post-high school education), sex, and Web experience (Web novice, Web expert). Participants reporting that they were "inexperienced" or "beginners" in terms of Internet knowledge were designated as "Web novices" and participants report "advanced" or "expert" Internet knowledge were designated as "Web experts."

Finally, participants' responses to the satisfaction questionnaire were tabulated as $\mathrm{n}$ and $\%$. All analyses were conducted with 
SAS, version 9.3, and all statistical tests were two-sided with a significance level of .05.

\section{Results}

Our study sample had a median age of 57 years and $61.9 \%$ of the participants were women. Participant characteristics according to study group are presented in Table 2. Individuals in the SA-SU group were younger than participants in the SU-SA group and more frequently reported an advanced or expert level in Internet knowledge. In terms of gender, educational level, occupational category, and type of Internet connection, no significant differences between groups were observed.

Table 3 presents performances on the different cognitive tasks according to time of administration of the cognitive battery (first administration versus second administration). Except for the time taken on the "Click" task and for the "Marbles" task composite variable, the performances on the cognitive tasks were systematically better for the second administration.

For illustrative purposes, performances on cognitive tests according to version of the test battery (self-administrated, supervised) are presented in Multimedia Appendix 1. Multimedia Appendix 2 shows Spearman correlations among the different cognitive test variables for the self-administered version of the test battery.

Table 4 shows Spearman correlation coefficients as measures of concordance between cognitive performances according to version. Spearman correlations ranged between .42 and .73. The lowest correlations were observed for the outcome variables "mean number of clicks" and "mean number of total errors" of the Maze task (Maze A and Maze B): here, Spearman correlation coefficients ranged between .42 and .43 .

Multimedia Appendix 3 shows Spearman correlation coefficients stratified by age group, educational level, sex, and Web experience. The coefficients ranged from .21-.80 and tended to be highest among participants who were higher educated and who had better Internet knowledge. However, these trends were not consistent across all outcome variables.

Tables 5 and 6 present the responses of participants to the satisfaction questionnaire. Notably, a majority of participants responded that they "absolutely" or "rather" agreed that the duration of the self-administered battery was acceptable $(184 / 185,99.5 \%)$, that the tasks were amusing $(162 / 185,87.6 \%)$, that the instructions were sufficiently detailed $(168 / 185,90.8 \%)$ and understandable $(164 / 185,88.7 \%)$, and that they had globally enjoyed the test battery $(182 / 185,98.4 \%)$. On the other hand, $81.1 \%(150 / 185)$ of participants reported to have preferred the supervised version of the self-administered version. 
Table 2. Participant characteristics $(\mathrm{N}=189)$.

\begin{tabular}{|c|c|c|c|c|c|}
\hline & \multicolumn{2}{|c|}{ Self-administered version first $(n=99)$} & \multicolumn{2}{|c|}{ Supervised version first $(\mathrm{n}=90)$} & \multirow[b]{2}{*}{$P^{\mathrm{b}}$} \\
\hline & $\mathrm{n}$ or $\mathrm{p} 50^{\mathrm{a}}$ & $\%$ or $\mathrm{p} 25 ; \mathrm{p} 75^{\mathrm{a}}$ & $\mathrm{n}$ or $\mathrm{p} 50^{\mathrm{a}}$ & $\%$ or $\mathrm{p} 25 ; \mathrm{p} 75^{\mathrm{a}}$ & \\
\hline Age & 55.0 & $40.0 ; 65.0$ & 59.0 & $51.0 ; 67.0$ & .02 \\
\hline Gender & & & & & .27 \\
\hline Male & 34 & 34.3 & 38 & 42.2 & \\
\hline Female & 65 & 65.7 & 52 & 57.8 & \\
\hline Education level & & & & & .74 \\
\hline$<2$ yrs post-high school education & 34 & 34.3 & 33 & 36.7 & \\
\hline$\geq 2$ yrs post-high school education & 65 & 65.7 & 57 & 63.3 & \\
\hline Occupational category & & & & & .50 \\
\hline Unemployed & 13 & 13.1 & 7 & 7.8 & \\
\hline Employee & 8 & 8.1 & 10 & 11.1 & \\
\hline Intermediate profession & 12 & 12.1 & 8 & 8.9 & \\
\hline Managerial staff ${ }^{c}$ & 38 & 38.4 & 32 & 35.6 & \\
\hline Retired & 28 & 28.3 & 33 & 36.7 & \\
\hline Self-evaluated Web knowledge d,e & & & & & .049 \\
\hline Web novice & 6 & 6.1 & 13 & 14.9 & \\
\hline Web expert & 92 & 93.9 & 74 & 85.1 & \\
\hline Type of connection ${ }^{d}$ & & & & & .94 \\
\hline$<512 \mathrm{k}$ & 9 & 9.2 & 9 & 10.3 & \\
\hline$\geq 512$ and $<1024 k$ & 18 & 18.4 & 16 & 18.4 & \\
\hline$\geq 1024 k$ & 48 & 49.0 & 39 & 44.8 & \\
\hline Do not know & 23 & 23.5 & 23 & 26.4 & \\
\hline
\end{tabular}

${ }^{\mathrm{a}}$ Values for age are not $\mathrm{n}$ and $\%$, but median and $25^{\mathrm{th}} ; 75^{\mathrm{th}}$ percentile.

${ }^{\mathrm{b}} P$ value for the difference between both administration order groups, from Wilcoxon rank-sum nonparametric tests for age and chi-square tests for other variables.

${ }^{\mathrm{c}}$ Or intellectual profession.

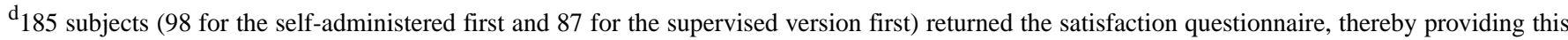
information.

eNovice: "inexperienced" or "beginner" level; expert: "advanced" or "expert" level. 
Table 3. Performance on cognitive tests: first versus second administration $(\mathrm{N}=189)^{\mathrm{a}}$.

\begin{tabular}{|c|c|c|c|c|c|c|}
\hline \multirow[b]{2}{*}{ Test $^{b}$} & \multirow[b]{2}{*}{ Variable } & \multicolumn{2}{|c|}{ First administration } & \multicolumn{2}{|c|}{ Second administration } & \multirow[b]{2}{*}{$P^{\mathrm{c}}$} \\
\hline & & $\mathrm{p} 50$ & p25; p75 & $\mathrm{p} 50$ & p25; p75 & \\
\hline Click & Time in seconds, mean & 4.29 & $3.64 ; 5.49$ & 4.32 & $3.68 ; 5.36$ & .70 \\
\hline \multicolumn{7}{|l|}{ Maze A } \\
\hline & Time in seconds, mean & 118.66 & $86.95 ; 168.67$ & 101.16 & $79.28 ; 129.76$ & $<.001$ \\
\hline & Clicks, mean n & 59.00 & $53.00 ; 70.33$ & 54.00 & $48.33 ; 60.67$ & $<.001$ \\
\hline & Total errors, mean $\mathrm{n}$ & 17.33 & $13.33 ; 25.00$ & 14.00 & $10.67 ; 18.00$ & $<.001$ \\
\hline \multicolumn{7}{|l|}{ Maze B } \\
\hline & Time in seconds & 85.35 & $62.87 ; 112.64$ & 72.11 & $51.72 ; 92.99$ & $<.001$ \\
\hline & Clicks, n & 48.00 & $42.00 ; 55.00$ & 44.00 & $37.00 ; 51.00$ & $<.001$ \\
\hline & Total errors, $\mathrm{n}$ & 10.00 & $7.00 ; 15.00$ & 8.00 & $4.00 ; 12.00$ & $<.001$ \\
\hline Cards & Composite variable $^{\mathrm{d}}$ & 1.26 & $1.09 ; 1.36$ & 1.28 & $1.15 ; 1.40$ & $<.001$ \\
\hline Marbles & Composite variable $^{\mathrm{d}}$ & 2.21 & $1.48 ; 3.31$ & 2.40 & $1.77 ; 3.33$ & .18 \\
\hline
\end{tabular}

${ }^{\mathrm{a}}$ Objective of this comparison: identification of potential learning effects. Lower scores indicate better performances, except for the Cards and Marbles composite variables, where higher scores indicate better performances.

${ }^{b}$ Maze A: Sum of the initial three rounds of the Maze task. Maze B: Final (fourth) round of the Maze task.

${ }^{\mathrm{c}}$ Wilcoxon signed-rank test (nonparametric paired test).

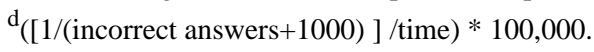

Table 4. Concordance of cognitive tests performances according to version $(\mathrm{N}=189)^{\mathrm{a}}$.

\begin{tabular}{|c|c|c|c|}
\hline \multirow[t]{2}{*}{ Test $^{\mathrm{b}}$} & \multirow[t]{2}{*}{ Variable } & \multicolumn{2}{|c|}{ Spearman correlation } \\
\hline & & $r$ & $P$ \\
\hline Click & Time in seconds, mean & .73 & $<.001$ \\
\hline \multicolumn{4}{|l|}{ Maze A } \\
\hline & Time in seconds, mean & .57 & $<.001$ \\
\hline & Clicks, mean n & .43 & $<.001$ \\
\hline & Total errors, mean $n$ & .43 & $<.001$ \\
\hline \multicolumn{4}{|l|}{ Maze B } \\
\hline & Time in seconds & .53 & $<.001$ \\
\hline & Clicks, $\mathrm{n}$ & .43 & $<.001$ \\
\hline & Total errors, $\mathrm{n}$ & .42 & $<.001$ \\
\hline Cards & Composite variable ${ }^{c}$ & .64 & $<.001$ \\
\hline Marbles & Composite variable ${ }^{c}$ & .51 & $<.001$ \\
\hline
\end{tabular}

${ }^{\mathrm{a}}$ Self-administered version versus supervised version.

${ }^{b}$ Maze A: Sum of the initial three rounds of the Maze task. Maze B: Final (fourth) round of the Maze task.

${ }^{\mathrm{c}}([1 /$ (incorrect answers+1000) $] /$ time $) * 100,000$. 
Table 5. Participant satisfaction with the two versions of the cognitive test battery, questions concerning the self-administered version $(\mathrm{N}=185)^{\mathrm{a}}$.

\begin{tabular}{llr}
\hline Questions & $\mathrm{n}$ & $\%$ \\
\hline The duration is acceptable & 145 & 78.4 \\
I absolutely agree & 39 & 21.1 \\
I rather agree & 1 & 0.5 \\
I rather don't agree & 0 & 0.0
\end{tabular}

The exercises can be rapidly finished

I absolutely agree

$\begin{array}{ll}64 & 34.6 \\ 112 & 60.5 \\ 8 & 4.3 \\ 1 & 0.5\end{array}$

The exercises are too simple

I absolutely agree

I rather agree

I rather don't agree

I absolutely don't agree

The exercises are amusing

I absolutely agree

I rather agree

I rather don't agree

I absolutely don't agree

The instructions are sufficiently detailed

I absolutely agree

I rather agree

I rather don't agree

I absolutely don't agree

The instructions are understandable

I absolutely agree

I rather agree

I rather don't agree

I absolutely don't agree

Overall, I have appreciated the test battery

$\begin{array}{llc}\text { I absolutely agree } & 83 & 44.9 \\ \text { I rather agree } & 99 & 53.5 \\ \text { I rather don't agree } & 3 & 1.6 \\ \text { I absolutely don't agree } & 0 & 0.0\end{array}$

I have had problems visualizing the graphics

$\begin{array}{lll}\text { I absolutely agree } & 2 & 1.1 \\ \text { I rather agree } & 7 & 3.8 \\ \text { I rather don't agree } & 49 & 26.5 \\ \text { I absolutely don't agree } & 127 & 68.7\end{array}$




\begin{tabular}{lll}
\hline Questions & $\mathrm{n}$ & $\%$ \\
\hline I absolutely agree & 155 & 83.8 \\
I rather agree & 30 & 16.2 \\
I rather don't agree & 0 & 0.0 \\
I absolutely don't agree & 0 & 0.0 \\
\hline
\end{tabular}

${ }^{\text {a } O n l y ~} 185$ out of the 189 participants of the study completed the satisfaction questionnaire.

Table 6. Participant satisfaction with the two versions of the cognitive test battery, questions concerning the supervised version, and comparison of the two versions $(\mathrm{N}=185)^{\mathrm{a}}$.

\begin{tabular}{|c|c|c|}
\hline Questions & $\mathrm{n}$ & $\%$ \\
\hline \multicolumn{3}{|c|}{ Questions concerning the supervised version } \\
\hline \multicolumn{3}{|l|}{ The duration is acceptable } \\
\hline I absolutely agree & 157 & 84.9 \\
\hline I rather agree & 28 & 15.1 \\
\hline I rather don't agree & 0 & 0.0 \\
\hline I absolutely don't agree & 0 & 0.0 \\
\hline \multicolumn{3}{|c|}{ I have appreciated completing the tests with a professional } \\
\hline I absolutely agree & 128 & 69.2 \\
\hline I rather agree & 56 & 30.3 \\
\hline I rather don't agree & 0 & 0.0 \\
\hline I absolutely don't agree & 1 & 0.5 \\
\hline \multicolumn{3}{|l|}{ Comparison of the two versions } \\
\hline \multicolumn{3}{|c|}{ Overall, which of the two versions have you preferred? } \\
\hline The Web version & 35 & 18.9 \\
\hline The supervised version & 150 & 81.1 \\
\hline
\end{tabular}

${ }^{\text {a } O n l y ~} 185$ out of the 189 participants of the study completed the satisfaction questionnaire.

\section{Discussion}

\section{Principal Findings}

The aim of this comparison study was to assess the concordance of the fully self-administered mode of the Web-based NutriCog test battery with a supervised mode of the same battery, characterized by the presence of a trained neuropsychologist. Nine different outcome variables were evaluated to measure the performance of participants on four different tasks (Click, Maze, Cards, and Marbles). Spearman coefficients for the correlation between the two modes of administrations, in terms of cognitive test performances, ranged between .42 and .73 . Correlation coefficients were lower for the Maze task (Mazes A and B) than for the other tasks. This could indicate potential problems concerning the comprehensibility of the Maze task instructions in the absence of a supervisor. However, based on suggestions made by the participants and by the neuropsychologist who was present during the supervised version of the test battery, these instructions have been slightly revised (after the comparison study was completed), in order to enhance understanding.
The observed correlation coefficients varied according to educational level and Web knowledge. Correlations tended to be higher among higher educated participants and among those with higher Internet knowledge. However, as can be expected in the context of an entirely Web-based study, there were only very few individuals who reported being "inexperienced" or having a "beginner level" with respect to Web knowledge.

Overall, in the context of this comparison study, very high values of concordance could not be expected due to multiple circumstances. First, we observed a clear learning effect, with test results that were almost systematically better at the second administration of the test battery, independently of the mode of administration. If such learning effects were of similar magnitude for the whole study sample, this would not affect the calculated Spearman correlations. On the other hand, differential learning effects would have lowered the observed concordance values in our sample. Further, cognitive performances are subject to a rather large amount of intra-individual variation [21].

To the best of our knowledge, no other study has yet investigated the concordance of a fully self-administered version of a cognitive test battery with a supervised version of the same test 
battery. However, the context of our study is similar to studies investigating test-retest reliability (ie, the correlation of performances on a first and a second administration of the same test battery), which have been conducted for multiple computerized cognitive batteries. A systematic review of the literature by Tierney et al identified 11 computerized cognitive test batteries [18], of which nine had information on the test-retest reliability for each subtest. The respective ranges of (Pearson or Spearman) correlation coefficients were .30-.74 (CAMCI) [22], .65-.88 (CANS-MCI) [23], .56-.90 (CNS Vital Signs) [24], .53-.93 (Cognitive Drug Research Computerized Assessment System for Dementia, COGDRAS-D) [25], .23-.79 (Cogstate) [26], .68-.80 (CSI) [27], .59-.98 (short form of the MicroCog battery) [28], and .40-.84 (Mindstreams Mild Impairment Battery) [29]. For the CANTAB battery, intraclass correlation coefficients were reported instead of Pearson or Spearman correlations, with a range of .09-.86 [30]. Of note, in our study, intraclass correlation coefficients (which were calculated after applying transformations to improve normality) ranged from .36-.65 (data not shown).

In this study, lower correlation coefficients than for such test-retest investigations had to be expected as we compared two different modes of administration. Although very high values of $\geq .9$ for specific subtests (as observed for the CNS Vital Signs, COGDRAS-D, and Microcog batteries) were not obtained in this investigation, the range of correlation coefficients found in our study (.42-.73) is roughly comparable to the ranges found in other studies.

Another element that supports the use of our Web-based cognitive battery in a fully self-administered mode is the fact that a majority $(88.7 \%)$ of participants evaluated the test instructions as sufficiently detailed and understandable. As stated above, in order to further improve the comprehensibility of the test battery, the instructions concerning the Maze task have been slightly modified by taking into account the suggestions of participants of this comparison study. Besides, $81.1 \%$ of participants preferred the supervised version of the battery to the self-administered version. However, this is probably largely due to the fact that social interaction with a health professional was perceived as a more pleasant situation than completing the test battery alone.

\section{Strengths and Limitations}

A certain number of limitations to this study have to be considered. First, the observed learning effect between the first and second administration of the test battery is difficult to separate from differences in cognitive performances that are related to the mode of administration. Second, this comparison study aimed only to compare the fully self-administered mode of the battery to a supervised mode of administration. Data on the ability of the battery to accurately discriminate normal cognitive function from impaired cognitive function are not available. An important strength of our study is its originality, as to the best of our knowledge, no other study has yet compared full self-administration to supervised administration of cognitive batteries. Moreover, the study was conducted within a rather large sample of 189 participants of varying age, sex, and educational level. Finally, the concordance between the two modes of administrations was assessed for the whole population as well as for specific subgroups.

\section{Conclusions}

The concordance of the self-administered version and the supervised version of the Web-based NutriCog cognitive test battery was roughly similar to that observed for test-retest investigations of other test batteries. This indicates that these two different modes of administration provide similar information. In large epidemiological studies like the NutriNet-Santé cohort, the objective of cognitive evaluations is not to provide data with high validity in a clinical context, but to measure cognitive performances in a rapid and simple manner, with sufficient quality to permit valid conclusions on the population level. Given the drastic reduction of the logistical and financial burden that can be obtained by using fully self-administered tools, Web-based cognitive test batteries such as NutriCog provide interesting alternatives to supervised tools in the context of large cohort studies.

\section{Acknowledgments}

The NutriNet-Santé study is supported by the French Ministry of Health, the Institut de Veille Sanitaire, the Institut National de Prévention et d'Education pour la Santé, the Fondation pour la Recherche Médicale, the Institut National de la Santé et de la Recherche Médicale, the Institut National de la Recherche Agronomique, the Conservatoire National des Arts et Métiers, and the Paris 13 University.

None of the funding bodies had any involvement in study design, in the collection, analysis and interpretation of the data, in writing the manuscript, or the decision to submit.

KEA was supported by a doctoral fellowship from the University of Paris 13.

We thank all the scientists, dietitians, technicians, and assistants who helped carry out the NutriNet-Santé study. We especially thank the computer scientists, Younes Esseddik, Yasmina Chelghoum, Mohand Ait Oufella, Paul Flanzy, and Thi Hong Van Duong, and the statisticians, Veronique Gourlet, Charlie Menard, Fabien Szabo, Nathalie Arnault, Laurent Bourhis, and Stephen Besseau. We are grateful to the volunteers of the NutriNet-Santé study.

\section{Authors' Contributions}

EKG and HA designed the comparison study (development of the concept, design and protocol of the study and coordination of data collection) and the investigated cognitive test battery (choice of tests to be included, coordination of the technical development, 
and the pilot testing). MB was responsible for the practical coordination and realization of the comparison study. KEA performed the statistical analysis and wrote the article. EKG, HA, and MB provided methodological guidance. SH is the principal investigator of the NutriNet-Santé study. KEA, MB, ACL, PG, SG, HA, and EKG were involved in interpreting the results and editing the manuscript for important intellectual content. EKG, $\mathrm{SH}$ and $\mathrm{HA}$ had full responsibility for the final content, including the presentation of the NutriCog test battery and its development. All authors read and approved the final manuscript.

\section{Conflicts of Interest}

None declared.

\section{Multimedia Appendix 1}

Performance on cognitive tests according to version.

[PDF File (Adobe PDF File), 31KB-Multimedia Appendix 1]

\section{Multimedia Appendix 2}

Spearman correlations between the different cognitive test variables for the self-administered version of the cognitive test battery NutriCog.

\section{[PDF File (Adobe PDF File), 37KB-Multimedia Appendix 2]}

\section{Multimedia Appendix 3}

Concordance of cognitive tests performances according to version: Spearman correlation coefficients, stratified by participant characteristics.

[PDF File (Adobe PDF File), 136KB-Multimedia Appendix 3]

\section{References}

1. Catalogue of United Nations Population Division Publications, Databases and Software 2003.: United Nations; 2002. World Population Ageing: 1950-2050, Chapter III: The changing balance between age groups URL: http://www.un.org/esa/ population/publications/worldageing19502050/ [accessed 2016-03-07] [WebCite Cache ID 6ZYD7Ob0T]

2. McGuire LC, Ford ES, Ajani UA. Cognitive functioning as a predictor of functional disability in later life. Am J Geriatr Psychiatry 2006 Jan;14(1):36-42. [doi: 10.1097/01.JGP.0000192502.10692.d6] [Medline: 16407580]

3. Alzheimer's Disease International. 2009. World Alzheimer Report URL: http://www.alz.co.uk/research/files/ WorldAlzheimerReport.pdf [accessed 2016-03-07] [WebCite Cache ID 6ZYDNprSM]

4. Mortimer JA, Borenstein AR, Gosche KM, Snowdon DA. Very early detection of Alzheimer neuropathology and the role of brain reserve in modifying its clinical expression. J Geriatr Psychiatry Neurol 2005 Dec;18(4):218-223 [FREE Full text] [doi: 10.1177/0891988705281869] [Medline: 16306243]

5. Amieva H, Le GM, Millet X, Orgogozo JM, Pérès K, Barberger-Gateau P, et al. Prodromal Alzheimer's disease: successive emergence of the clinical symptoms. Ann Neurol 2008 Nov;64(5):492-498. [doi: 10.1002/ana.21509] [Medline: 19067364]

6. Amieva H, Jacqmin-Gadda H, Orgogozo J, Le CN, Helmer C, Letenneur L, et al. The 9 year cognitive decline before dementia of the Alzheimer type: a prospective population-based study. Brain 2005 May;128(Pt 5):1093-1101 [FREE Full text] [doi: 10.1093/brain/awh451] [Medline: 15774508]

7. DeKosky ST, Marek K. Looking backward to move forward: early detection of neurodegenerative disorders. Science 2003 Oct 31;302(5646):830-834. [doi: 10.1126/science.1090349] [Medline: 14593169]

8. Linn RT, Wolf PA, Bachman DL, Knoefel JE, Cobb JL, Belanger AJ, et al. The 'preclinical phase' of probable Alzheimer's disease. A 13-year prospective study of the Framingham cohort. Arch Neurol 1995 May;52(5):485-490. [Medline: 7733843]

9. Coley N, Andrieu S, Gardette V, Gillette-Guyonnet S, Sanz C, Vellas B, et al. Dementia prevention: methodological explanations for inconsistent results. Epidemiol Rev 2008;30:35-66. [doi: 10.1093/epirev/mxn010] [Medline: 18779228]

10. Middleton LE, Yaffe K. Promising strategies for the prevention of dementia. Arch Neurol 2009 Oct;66(10):1210-1215 [FREE Full text] [doi: 10.1001/archneurol.2009.201] [Medline: 19822776]

11. Singh-Manoux A, Kivimäki M. The importance of cognitive aging for understanding dementia. Age (Dordr) 2010 Dec;32(4):509-512 [FREE Full text] [doi: 10.1007/s11357-010-9147-7] [Medline: 20454932]

12. Lee KS, Eom J, Cheong H, Oh BH, Hong CH. Effects of head circumference and metabolic syndrome on cognitive decline. Gerontology 2010;56(1):32-38. [doi: 10.1159/000236028] [Medline: 19729879]

13. Fratiglioni L, Paillard-Borg S, Winblad B. An active and socially integrated lifestyle in late life might protect against dementia. Lancet Neurol 2004 Jun;3(6):343-353. [doi: 10.1016/S1474-4422(04)00767-7] [Medline: 15157849]

14. Hughes T, Ganguli M. Modifiable midlife risk factors for late-life dementia. Rev Neurol 2010 Sep 1;51(5):259-262 [FREE Full text] [Medline: 20669124] 
15. Rooney RFE. Preventing dementia: how lifestyle in midlife affects risk. Curr Opin Psychiatry 2014 Mar;27(2):149-157. [doi: 10.1097/YCO.0000000000000045] [Medline: 24441418]

16. Lezak M, Howieson D, Bigler ED, Tranel DD. Neuropsychological Assessment. New York: Oxford University Press; 2004.

17. Wild K, Howieson D, Webbe F, Seelye A, Kaye J. Status of computerized cognitive testing in aging: a systematic review. Alzheimers Dement 2008 Nov;4(6):428-437 [FREE Full text] [doi: 10.1016/j.jalz.2008.07.003] [Medline: 19012868]

18. Tierney MC, Lermer MA. Computerized cognitive assessment in primary care to identify patients with suspected cognitive impairment. J Alzheimers Dis 2010;20(3):823-832 [FREE Full text] [doi: 10.3233/JAD-2010-091672]

19. Depp C, Harmell A, Vahia I. Successful cognitive aging. Curr Top Behav Neurosci 2012;10:35-50. [doi: $\underline{10.1007 / 7854} 2011$ 158] [Medline: $\underline{22275006}$ ]

20. Pietrzak RH, Maruff P, Mayes LC, Roman SA, Sosa JA, Snyder PJ. An examination of the construct validity and factor structure of the Groton Maze Learning Test, a new measure of spatial working memory, learning efficiency, and error monitoring. Arch Clin Neuropsychol 2008 Jul;23(4):433-445 [FREE Full text] [doi: 10.1016/j.acn.2008.03.002] [Medline: 18448309]

21. Salthouse TA, Nesselroade JR, Berish DE. Short-term variability in cognitive performance and the calibration of longitudinal change. J Gerontol B Psychol Sci Soc Sci 2006 May;61(3):P144-P151 [FREE Full text] [Medline: 16670183]

22. Saxton J, Morrow L, Eschman A, Archer G, Luther J, Zuccolotto A. Computer assessment of mild cognitive impairment. Postgrad Med 2009 Mar;121(2):177-185 [FREE Full text] [doi: 10.3810/pgm.2009.03.1990] [Medline: 19332976]

23. Tornatore JB, Hill E, Laboff JA, McGann ME. Self-administered screening for mild cognitive impairment: initial validation of a computerized test battery. J Neuropsychiatry Clin Neurosci 2005;17(1):98-105 [FREE Full text] [doi: 10.1176/jnp.17.1.98] [Medline: 15746489]

24. Gualtieri CT, Johnson LG. Reliability and validity of a computerized neurocognitive test battery, CNS Vital Signs. Arch Clin Neuropsychol 2006 Oct;21(7):623-643 [FREE Full text] [doi: 10.1016/j.acn.2006.05.007] [Medline: 17014981]

25. Simpson P, Surmon D, Wesnes K, Wilcock G. The cognitive drug research computerized assessment system for demented patients: A validation study. Int J Geriat Psychiatry 1991 Feb;6(2):95-102. [doi: 10.1002/gps.930060208]

26. Collie A, Maruff P, Darby DG, McStephen M. The effects of practice on the cognitive test performance of neurologically normal individuals assessed at brief test-retest intervals. J Int Neuropsychol Soc 2003 Mar;9(3):419-428. [doi: 10.1017/S1355617703930074] [Medline: $\underline{12666766]}$

27. Erlanger DM, Kaushik T, Broshek D, Freeman J, Feldman D, Festa J. Development and validation of a web-based screening tool for monitoring cognitive status. J Head Trauma Rehabil 2002 Oct;17(5):458-476. [Medline: 12802255]

28. Elwood RW. MicroCog: assessment of cognitive functioning. Neuropsychol Rev 2001 Jun;11(2):89-100. [Medline: 11572473]

29. Schweiger A, Doniger GM, Dwolatzky T, Jaffe D, Simon ES. Reliability of a novel computerized neuropsychological battery for mild cognitive impairment. Acta Neuropsychologica 2003;1(4):407-413.

30. Lowe C, Rabbitt P. Test/re-test reliability of the CANTAB and ISPOCD neuropsychological batteries: theoretical and practical issues. Cambridge Neuropsychological Test Automated Battery. International Study of Post-Operative Cognitive Dysfunction. Neuropsychologia 1998 Sep;36(9):915-923. [Medline: 9740364]

\section{Abbreviations}

CAMCI: Computer Assessment of Mild Cognitive Impairment

CANS-MCI: Computer-Administered Neuropsychological Screen for Mild Cognitive Impairment

CANTAB: Cambridge Neuropsychological Test Automated Battery

CNS Vital Signs: Central Nervous System Vital Signs

COGDRAS-D: Cognitive Drug Research Computerized Assessment System for Dementia

MicroCog: MicroCog: Assessment of Cognitive Functioning

SA-SU: self-administered version first, supervised version second

SU-SA: supervised version first, self-administered version second

Edited by G Eysenbach; submitted 01.07.15; peer-reviewed by R Pamphlett, J Parkin Kullmann; comments to author 29.07.15; revised
version received 12.08.15; accepted 15.08.15; published 05.04.16
Please cite as:
Assmann KE, Bailet M, Lecoffre AC, Galan P, Hercberg S, Amieva H, Kesse-Guyot E
Comparison Between a Self-Administered and Supervised Version of a Web-Based Cognitive Test Battery: Results From the
NutriNet-Santé Cohort Study
JMed Internet Res $2016 ; 18(4): e 68$
URL: $\underline{\text { http://www.jmir.org/2016/4/e68/ }}$
doi: $10.2196 / j m i r .4862$
PMID: 27049114


(CKaren E Assmann, Marion Bailet, Amandine C Lecoffre, Pilar Galan, Serge Hercberg, Hélène Amieva, Emmanuelle Kesse-Guyot. Originally published in the Journal of Medical Internet Research (http://www.jmir.org), 05.04.2016. This is an open-access article distributed under the terms of the Creative Commons Attribution License (http://creativecommons.org/licenses/by/2.0/), which permits unrestricted use, distribution, and reproduction in any medium, provided the original work, first published in the Journal of Medical Internet Research, is properly cited. The complete bibliographic information, a link to the original publication on http://www.jmir.org/, as well as this copyright and license information must be included. 